\title{
WCCC 2016: The 22nd World Computer Chess Championship
}

\author{
Jan Krabbenbos ${ }^{\mathrm{a}}$, Jaap van den Herik ${ }^{\mathrm{b}}$ and Guy Haworth ${ }^{\mathrm{c}, *}$ \\ a Amersfoort, The Netherlands \\ ${ }^{\mathrm{b}}$ Faculties of Law and Science, Leiden University, Leiden, The Netherlands \\ ${ }^{\mathrm{c}}$ University of Reading, Reading, $U K$
}

The 22nd World Computer Chess Championship started on June 27, 2016. Six programs participated in a double round robin tournament, see Table 1 (CPW 2016a-u; Krabbenbos et al., 2016). The tournament took place at Leiden University and was organized by the ICGA, LIACS and LCDS. It was sponsored by Google, Naturalis Biodiversity Center, the municipality of Leiden, Leiden University, its Faculty of Science, the ICGA, iSSC, SurfSara, Digital Game Technology and NWO Exact Sciences. It was held in conjunction with the 19th Computer Olympiad and the 15th Advances in Computer Games conference. The openings' ECO codes are noted and Figs. 1-10 give positions from Rounds 1-10 respectively. The classical tempo was $1 \mathrm{~h} 45^{\prime}+15^{\prime} / \mathrm{move}$ for both sides.

Table 1

The WCCC 2016 participants

\begin{tabular}{|c|c|c|c|c|c|c|c|c|}
\hline & Program & Author(s) & Country & Operator & Cores & Threads & Architecture & $\mathrm{GHz}$ \\
\hline 1 & GRIDGINKGO & $\begin{array}{l}\text { Frank Schneider, Kai } \\
\text { Himstedt and Robert } \\
\text { Hyatt }\end{array}$ & $\mathrm{DE}$ & $\begin{array}{l}\text { Timo Haupt, Kai } \\
\text { Himstedt }\end{array}$ & 224 & 224 & AMD \& Intel & $\sim 3$ \\
\hline 2 & HIARCS & Mark Uniacke & GB & $\begin{array}{c}\text { Harvey Williamson, } \\
\text { Hans v.d. Zijden }\end{array}$ & 27 & 27 & Intel Xeon E5-2697 & 2.7 \\
\hline 3 & JONNY & Johannes Zwanzger & $\mathrm{DE}$ & Johannes Zwanzger & 2,400 & 2,376 & AMD x86-64 & 2.8 \\
\hline 4 & KOMODO & $\begin{array}{l}\text { Don Dailey, Larry } \\
\text { Kaufman and Mark } \\
\text { Lefler }\end{array}$ & USA & $\begin{array}{l}\text { Mark Lefler \& } \\
\text { Erdogen Günes }\end{array}$ & 48 & 48 & Intel i7 & 2.8 \\
\hline 5 & RAPTOR & Steve Webber & USA & Wolfgang Zugrav & 12 & 12 & Intel Xeon X5680 & 4.1 \\
\hline 6 & SHREDDER & Stefan Meyer-Kahlen & $\mathrm{DE}$ & Stefan Meyer-Kahlen & 32 & 32 & Intel I5-2697 & 2.6 \\
\hline
\end{tabular}

Round 1: Hiarcs - Jonny 0-1 (D10), RAPTOR - ShredDer 0-1 (E06), KoMOdo - GridGinkgo 1-0 (A28).

\footnotetext{
*Corresponding author: Guy Haworth, 33, Alexandra Rd., Reading, RG1 5PG, UK. Tel.: +44 118 9268994; E-mail: guy.haworth@bnc.oxon.org.
} 
Being the world champion meant that in the first round all eyes were directed to JonNy. During the opening JONNY was welcomed with applause and in the drawing of lots JONNY was privileged to be the first up and drew number 6. When the round started, Hiarcs had White and the game opened with 1. d4 d5 2. c4 c6 3. g3. In this position the world champion program was out of book and took 41 minutes for its reply. In the end the move was nothing other than 3. dxc4. Of course JonNy had computed many consequences and played the next twenty moves rather quickly. By move 25, Hiarcs had spent 15 minutes of thinking time more than Jonny. Meanwhile the game had been exciting. On move 19 White decided to open the position since it believed that it could achieve advantage by opening the f-file and using the diagonal c8-h3. Black played the ingenious move 20. . . Bg5, which after capture and recapture led to the position of Fig. 1a. White played 22. Nf6+ winning the black queen for rook and knight. The resultant position was evaluated as a draw by both programs. However evaluating is one thing, playing moves is another. The innocent looking move $\mathbf{3 1}$. $\mathbf{3}$ turned out to be the decisive mistake, since it gave Black the dominant position on all white squares. The only point of attention for Black was not to exchange the rooks since RRB-v-QR is stronger than RB-v-Q for the side without the queen. JONNY exploited the opportunities given to the program excellently. This game promised an exciting tournament.
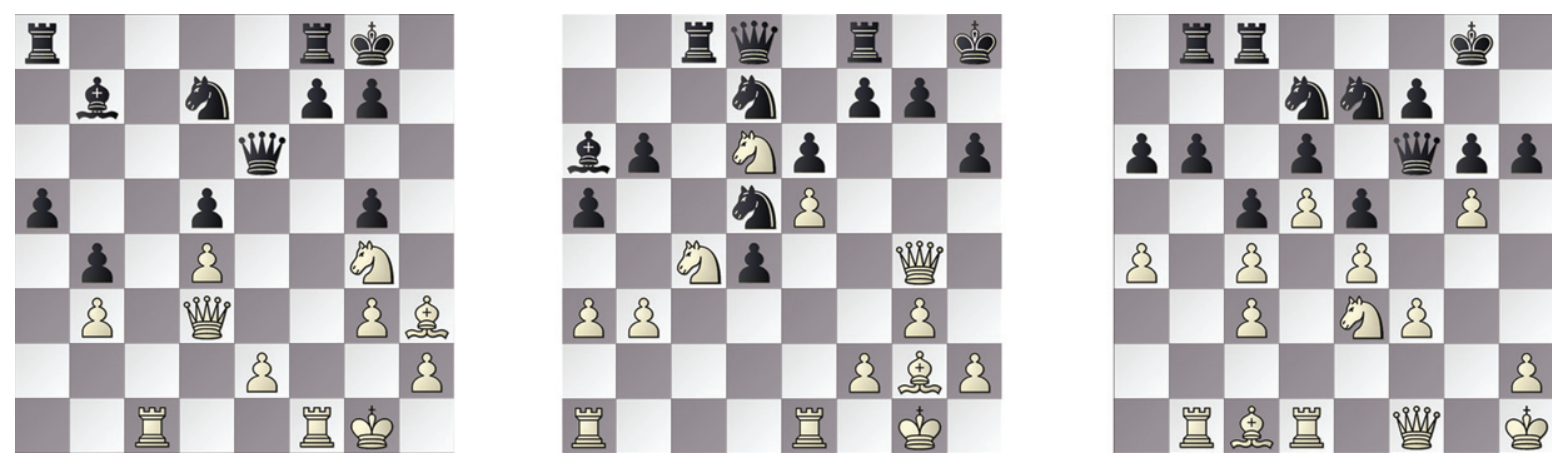

Fig. 1. R1: a) Hiarcs - Jonny 22w, b) RAPTOR - SHredDer 21 b and c) Komodo - GridGinkgo 25 b.

In the game RAPTOR - SHREDDER a closed Catalan was the start of a tough fight. White played ambitiously and sacrificed a pawn for some play on the kingside. There was no real threat but White managed to enter the black position with its knight: it looked convincing. However Black sacrificed the exchange, see Fig. 1b, and gained a second pawn. That was a good decision since from then on the position could be considered a win for Black. The play by SHREDDER was impeccable and the win was fully deserved.

The game Komodo - GrIDGINKGo shows the intricacies of the English Four Knights opening. White played dynamically but Black countered very well and seemed to have quite an acceptable position. In a difficult middlegame White manoeuvred adequately, but nothing seemed to be special. However White computed quite deeply and found an interesting move 25. g5, see Fig. 1c, which opened the g-line towards the black king and underlined the weaknesses of h6 and f6. Yet, Black defended its position ingeniously. For a long time the white bishop on h6 seemed to be on the wrong square but here 
again, White had computed the position and the corresponding variations very accurately. It brought Komodo the first win in this tournament.

Round 2: JoNnY - GRIDGinkgo 1/2-1/2 (E11), ShredDER - KOMODO 1/2-1/2 (D90), HiARCS - RAPTOR 1-0 (C43).

It is fascinating to see how creatively computers play nowadays. In comparison to human players they almost relentlessly continue to find new ways to confront the opponent with challenges to overcome. World champion JONNY is a front-runner in this style of play. In its game against GRIDGINKGO, JoNNY followed the lines of the well-known Bogo-Indian opening. Obviously Black was well prepared and many inventive attacks on squares by JONNY were answered by adequate counterplay. In the position of Fig. 2a JONNY started an attack on the kingside, mainly in order to gain territory. Black regrouped its pieces to a sufficient extent and countered by threats to invade White's position. In human terms the game seemed to sway back and forth but in computer terms we may assume that the computers had a deep understanding of the position and saw almost everything. Whatever the tries performed on both sides, the equilibrium was never broken and led to a well-deserved draw.
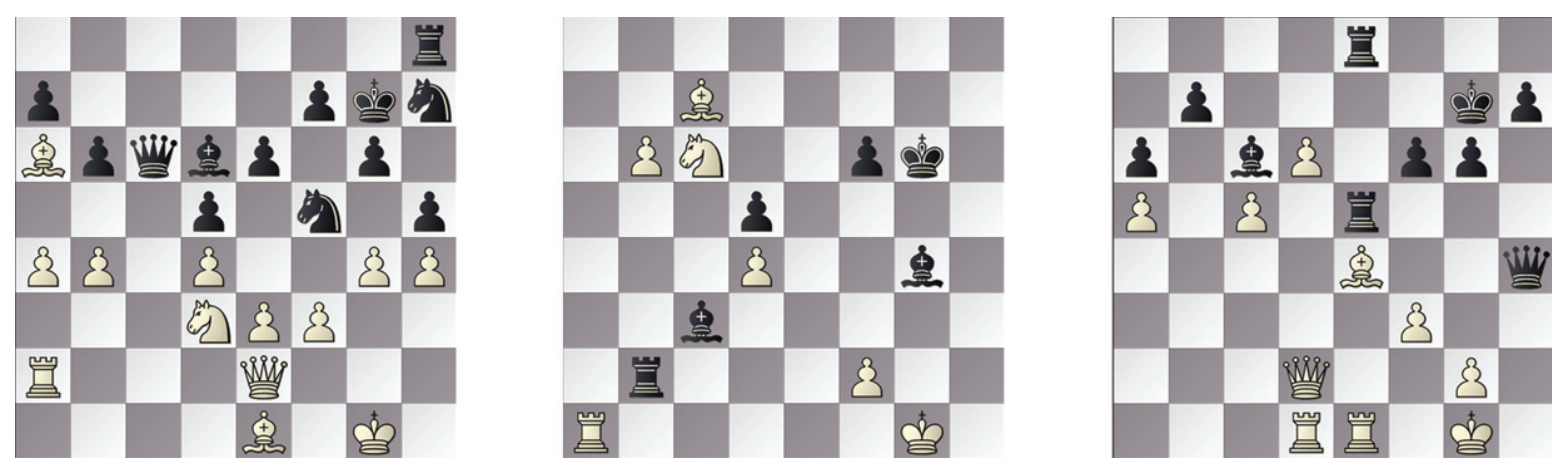

Fig. 2. R2: a) Jonny - GridGinkgo 47b, b) Shredder - Komodo 44b and c) Hiarcs - Raptor 35 w.

The game SHredDer - Komodo started as a Gruenfeld, Schlechter variation. Both sides played the opening along the usual lines. SHREDDER gained a pawn and tried to keep that pawn as an asset for a win in the far future. White was even able to run with the passed b-pawn along the b-file. The only possibility for Black was a counter attack on the queenside. The attack was not really furious but Black was able to exchange many pawns on that side of the board. The limited number of pieces led to a very interesting endgame. White was still a pawn up; Black had the advantage of mobile pieces. The activity of the black pieces guaranteed sufficient counterplay. When White tried too hard it compromised its position, see Fig. 2b. However the material advantage was not enough for Black to win. The result was that bishop plus pawn against bishop plus bishop ended in a draw.

In the game HIARCS - RAPTOR we saw an unequal fight. The stronger side played the opening very well and entered the midgame with a comfortable position. Black had to take into account many possible invasions. For a long time it looked like Black had a reply for all White's attacks but in reality its position became weaker and weaker. White continued to play well, see Fig. 2c, and succeeded in penetrating the black position with king and rook. Accordingly, Black resigned. 
Round 3: RaPtor - Jonny 0-1 (C54), Komodo - Hiarcs 1-0 (A32), GridGinkgo - Shredder 0-1 (D12).

RAPTOR played a quiet opening, named the Giuco Piano in Italian, against the world champion. Although the forces on both sides engaged with each other tardily, it was clear that Black had collected all kinds of small advantages by that time. Move 18. cxb4, see Fig. 3a, was the first of two weak moves in succession. With the second capture on b4 White was definitely facing weaknesses on its queenside. Possibly 18. c4 was a better move. The advantage so achieved was sufficient and JoNNY exploited it to its full extent. Without any uncertainties en route, Black managed to collect the full point from this encounter.
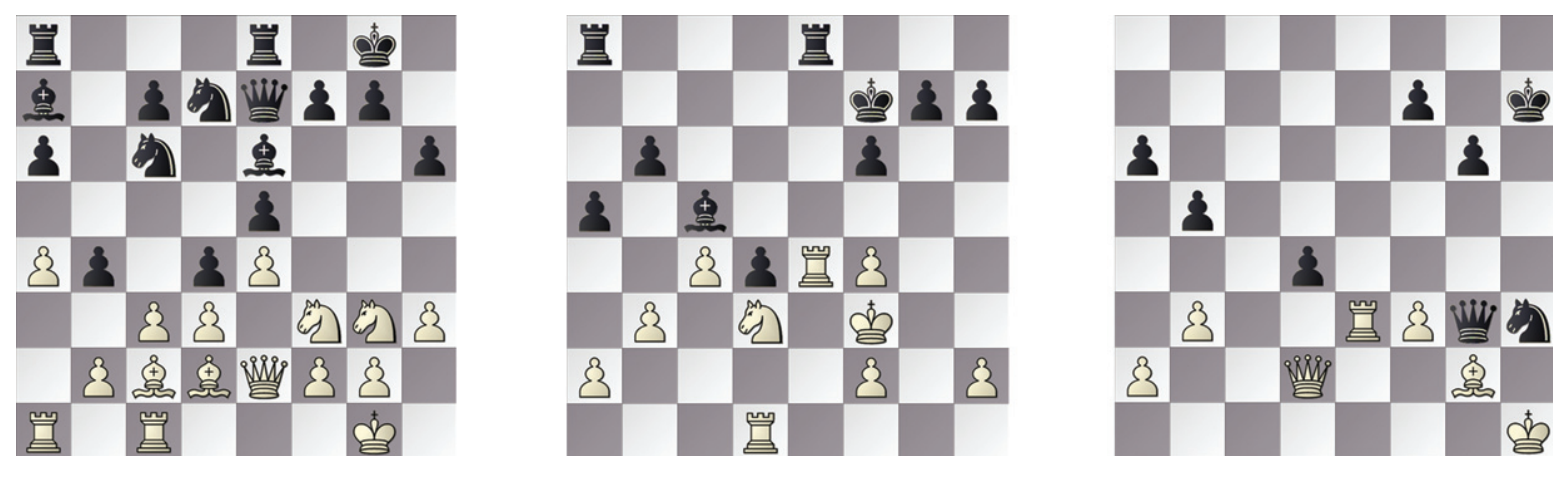

Fig. 3. R3: a) RAPtOr - Jonny 18w, b) Komodo - Hiarcs 27w and c) GridGinkgo - Shredder $46 \mathrm{~b}$.

KomOdO - HiARCS was a game between two tough opponents. Both programs have excellent pedigree and a clash of ideas was expected. The game started smoothly with an English opening and for a long time the main motif of the game was not clear. However on move 27 White played f4-f5, see Fig. 3b, which opened the possibility of a king walk into Black's position. This dominant feature decided the game. The continuation as followed by Black underlines the idea and we see that penetration is more important than capturing a pawn. The way White completed the game deserves applause.

It is astonishing to see how SHREDDER harmoniously combines strong moves into plans and vice versa, executes strong moves within plans designed earlier. In the game against GRIDGINKGO the spectator was captured from the beginning by the sequences of moves. After a sequence of four or five moves the spectator realizes that he has seen a nice plan. The sequence of plans then is a natural view which has everything to do with playing strength. SHREDDER is a very strong program. For those who did not know that, this game is a telling example. In particular the finale is a beauty for the eye. See the Fig. 3c and enjoy the move 46. ... Qf2. The game is over: our compliments to SHREDDER!

Round 4: Jonny - Shredder 1-0 (D46), HiarCs - GridGinkgo 1/2-1/2 (C53), RaPtor - Komodo $1 / 2-1 / 2(\mathrm{~A} 83)$.

The game between Jonny and SHREDDER started as a Semi-Slav. The exchange of bishop for knight at the end of the opening phase is well-known. Still, it gave White the small advantage of having two bishops. Later it became even more relevant as the other black bishop was also exchanged against the knight. Having the pair of bishops was a clear advantage in the positions that appeared on the board. Nevertheless, the fight could have gone on had Black taken the right decision on move 31 by 
playing 31. ... Kh7, see Fig. 4a. After the move played, 31. ... Kh8, White had a clear advantage and managed to convert this into a win.

The game HIARCS - GRIDGINKGO started slowly with the Italian Giuco Piano opening. The pieces found their places and also found possibilities to be exchanged. It looked like an easy draw. But suddenly on move 42 White started marching its king towards the opponent's king by playing Kh2-g3-g4-g5. It was a surprising manoeuvre, see Fig. 4b. The freeing move was g2-g4. The recapture by the king brought things back to a normal situation. This implied material balance and positional equality so the game ended in a draw.
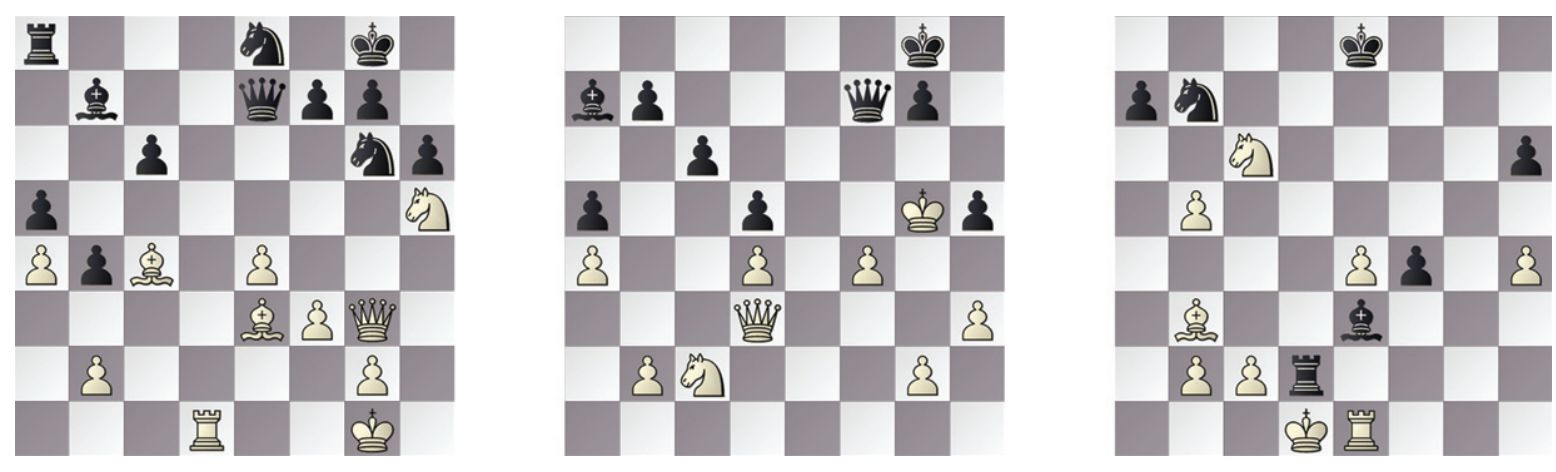

Fig. 4. R4: a) Jonny - Shredder 31b, b) Hiarcs - GridGinkgo 44b and c) RAPTOR - Komodo 31w.

The game RAPTOR - KOMODO started full of expectations as the Staunton Gambit was played. Both sides followed the theoretical line which is known to lead to equal play. Both programs knew the strategic lines to be followed but as we all know, the challenge of chess is in its subtleties. Black tried to outclass White in a tactical way. However White took the pawns offered and decided to defend as best it could. As White did well, Black decided to look for a repetition and found it on move 30, see Fig. 4c, by forcing a direct repetition of moves for a draw.

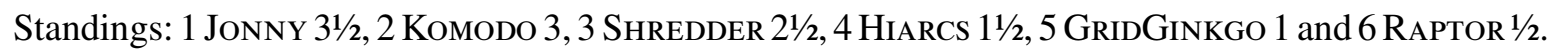

Round 5: Komodo - Jonny 1-0 (C54), GridGinKGo - RAPTOR 1-0 (A34), SHREdDER - Hiarcs 1-0 (D46).

Chess is a game of sequences of moves. The sequence should be good which implies that the moves in the sequence should be good. From this statement it is also clear that a good move should belong to the sequence, the chosen strategic idea that is relevant for the position. This statement is certainly true for the game Komodo - JonNy. Komodo played the right moves in connection with each other whereas play by JONNY could be characterized as producing good moves without ensuring that the moves had the required strategic connection with each other. So it happened that JoNNY found itself in a worse position, see Fig. 5a, and then did not play the best move, namely 45. ... Kf8. This allowed White to bring the bishop from e 3 to a3 from where it had the black king directly under fire. The advantage so achieved was sufficient for a white win.

In the game GRIDGINKGO - RAPTOR the opening was strategic and the game was equal for a long time. Black pushed for a decision on White's centre. GRIDGINKGO took the unusual step of giving up its direct influence on the centre by capturing on c5. Now a subtle exchange of strategies took 

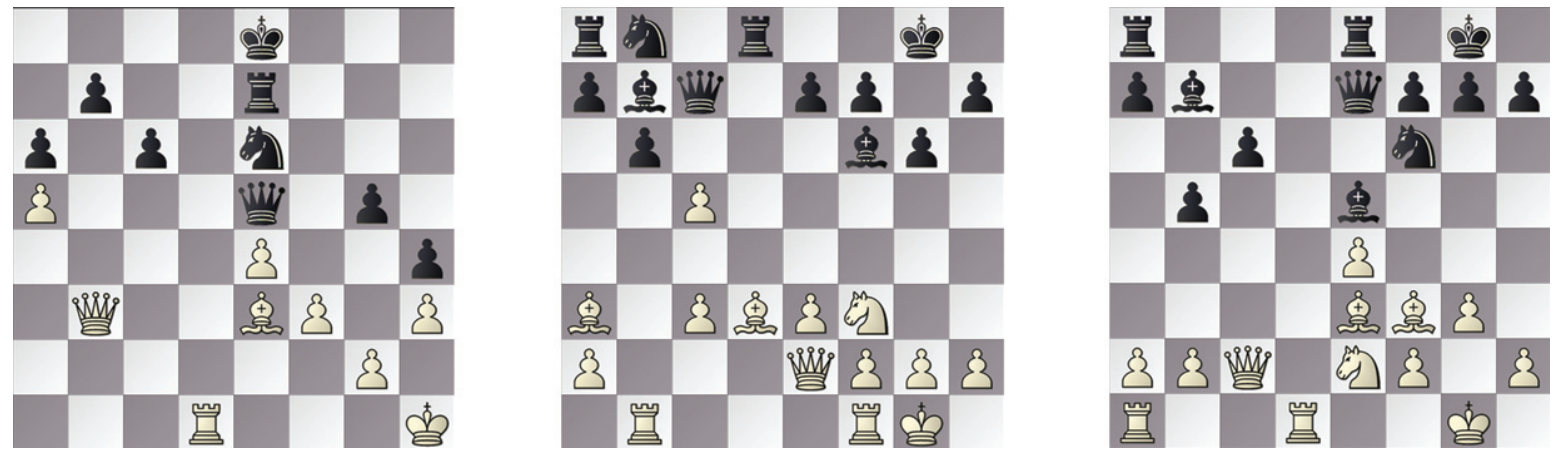

Fig. 5. R5: a) Komodo - Jonny 45b, b) GridGinkgo - Raptor 14w and c) Shredder - Hiarcs $18 \mathrm{~b}$.

place. Black did not recapture but used the pawn to attempt to increase the tension on that part of the board, see Fig. 5b. Superficially it looked alright because Black had rather good compensation. Nevertheless White found ways to keep the pawn, recover the position and enable some exchanges. The more exchanges occurred on the board, the more valuable the advantage of the pawn became. Finally it was the key to the white win.

The game Shredder - Hiarcs was a Semi Slav. From the opening Black had to fight for an equal position and for a long time seemed to succeed. However the more the game progressed, the harder Black had to work to maintain equality. A well thought out temporary sacrifice of a pawn seemed to free its position before c6-c5, see Fig. 5c. But White had seen more deeply and after Black had regained the pawn we saw a slight advantage for White. Now SHREDDER showed its power. The small advantage became steadily larger and finally it was transformed into a position with a pawn up. That position required utmost care but SHREDDER proved itself to be a master in such configurations and deservedly won the game.

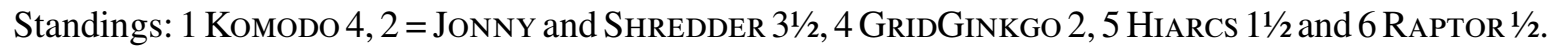

Round 6: Jonny - Hiarcs 1-0 (D45), Shredder - RAPTOR 1-0 (E90), GridGinkgo - Komodo 1/2-1/2 (A40).

The game JonNy - Hiarcs is a nice example for people who believe in the strength of two well coordinated knights in relation to a pair of bishops. In this game JONNY was the conductor of the knights. The bishops were outclassed and the knights created threats, dangers and destruction. A telling situation is shown in Fig. 6a. Black might have envisaged that it could now eliminate one of the knights but the pawn on f5 is even stronger. For JoNNY it was an easy game and for the public it is nice to replay the game to see the techniques available to the program. JONNY took a direct route to the win.

SHREDDER saw its opponent playing the Kings Indian. It is one of the most difficult openings in chess. RAPTOR playing Black reached a normal midgame with Kings Indian characteristics. In that situation the real fight began. White was forced to play its rook up the d-file. The program did so with a nice combination. It gained the small exchange in return for two pawns, see Fig. 6b before g2-g4. Moreover White's evaluation of the resulting position was superior. The pawns did not have any impact whereas the two pieces were superior to the rook. SHREDDER outplayed RAPTOR in this phase and brought the full point home. 

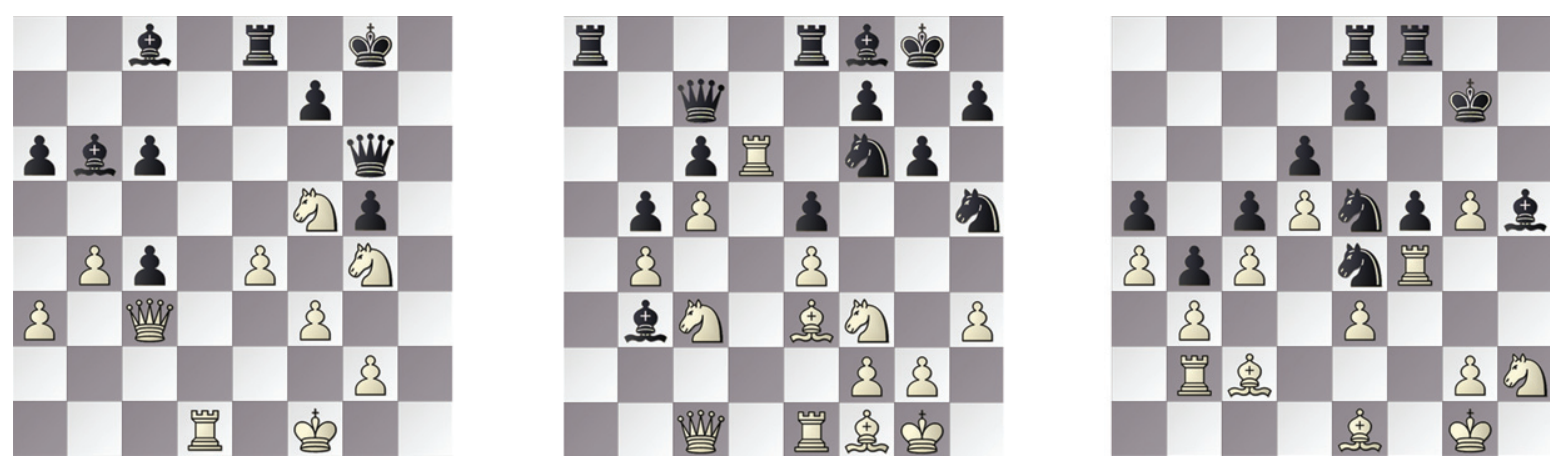

Fig. 6. R6: a) JonNy - Hiarcs 33b, b) SHREdDER - RAPtor 22w and c) GridGinkgo - Komodo 41 b.

The game GRIDGINKGO - Komodo showed that the Leningrad variation of the Dutch opening is still playable. It resulted in a direct fight which was strategic in general and only sometimes locally tactical. Both programs were well prepared and took into account the opponent's ideas. Anticipation played a nice role but some would argue that anticipation is prophylactic and therefore there was never a real clash in this game. On move 41, see Fig. 6c, Black tried to change the character of the position by playing 41. ... Nc3. Although White accepted the challenge and we saw a new pawn structure with new strong and weak points it did not have any impact on the winning chances of either side. After some fifty more moves the game ended in a draw by repetition.

Standings: $1=$ Komodo, Jonny and Shredder 41/2, 4 GridGinkgo 21/2, 5 Hiarcs $1 \frac{1}{2} 2$ and 6 RAPTOR $1 / 2$.

Round 7: GridGinkgo - Jonny 0-1 (C78), Komodo - Shredder 1/2-1/2 (B21), Raptor - Hiarcs $1 / 2-1 / 2(A 20)$.

In the game GRIDGINKGO - JONNY the Ruy Lopez dominated the position well into the middlegame. White was a pawn up but with a doubled pawn: Black had dynamic play for its pieces. The evaluation of the position was clear: some small advantage for Black. However the question was how to materialize such an advantage. For instance the two black bishops in this game were stronger than the two knights but expressing this advantage in a substantial way relevant to winning the game was difficult. Yet Black found a nice idea which materialized, see Fig. 7a, with 51. ... g5 followed by g5-g4, thereafter destroying White's pawn structure. From that point onwards the win transpired slowly but decidedly on the board. A nice performance by JONNY.

Komodo - ShredDER started as a real fight with Sicilian flavor. By a move to move evaluation it might be possible to find some evaluations departing from zero. The general impression for readers is however that this game is one of equal forces. It was good to see both sides trying to achieve some advantage but the opponents turned out to be of equal strength. Still Black seem to manage a slight advantage by a more harmonious structure and a good consolidation of what had been achieved. White must have noticed this also and decided to take an exit that led to a draw. In did so by a rook sacrifice, see Fig. 7b, followed by a perpetual check.

Some drawn games are the result of quiet play. Others are the result of furious trials to make something out of nothing. The game RAPTOR - HiARCS belongs to the last category: Hiarcs played for the win. This is most observable in Fig. 7c where play proceeded 24. ... Qg5 25. Rxb7 Bxh3 26. Bf1. However 

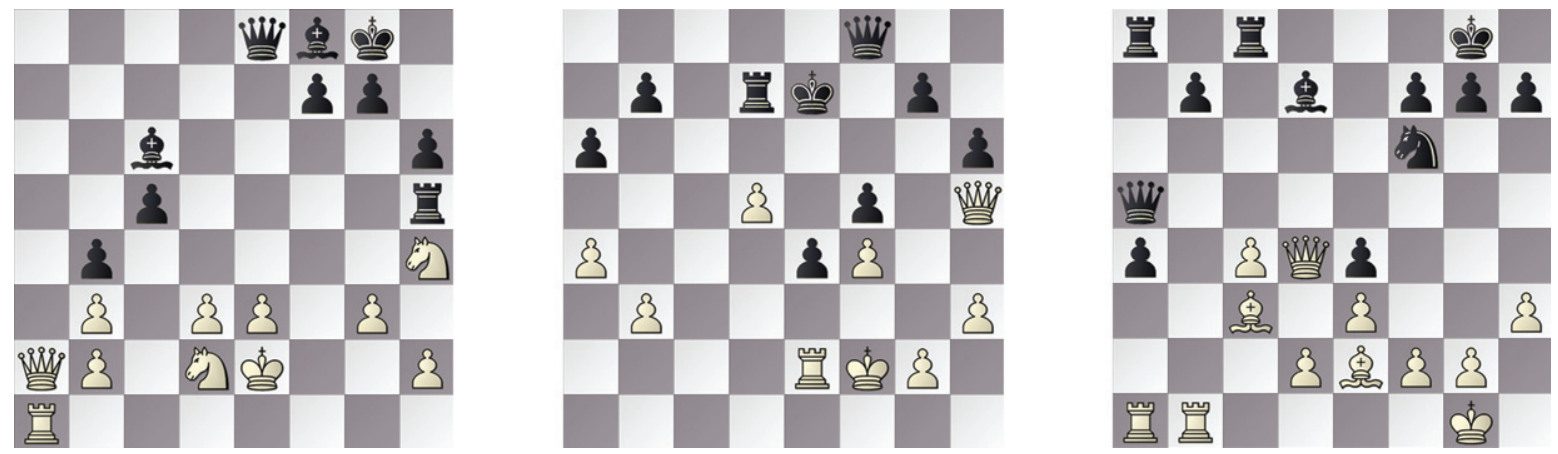

Fig. 7. R7: a) GridGinkgo - Jonny 51b, Komodo - Shredder 44w and c) Raptor - Hiarcs $24 b$.

the attempt did not work out well enough: Black was unable to follow up its threats on the white king. After this intermezzo the game resumed with some piece exchanges and finally an endgame was reached where the programs agreed to a draw.

Standings: 1 Jonny 51/2, 2=Komodo and Shredder 5, 4 GridGinkgo 21/2, 5 Hiarcs 2 and 6 RAPTOR 1.

Round 8: JONNY - RAPTOR 1-0 (D24), HiARCS - KOMODO 0-1 (B15), SHREDDER - GRIdGinKGO 1/2-1/2 (D45).

JONNY - RAPTOR was a Queens Gambit Accepted. The variations are well known and the moves played are almost never new. Still both contenders managed to leave the trodden paths. World champion JoNNY believed that this was an opponent that could be walked over by a simple attack. Therefore it played 16. Bxh6 in the position of Fig. 8a. Matters were not as simple as envisioned but the inventive play by White secured the win which took place on move 53. JonNy established itself in the lead with this win.
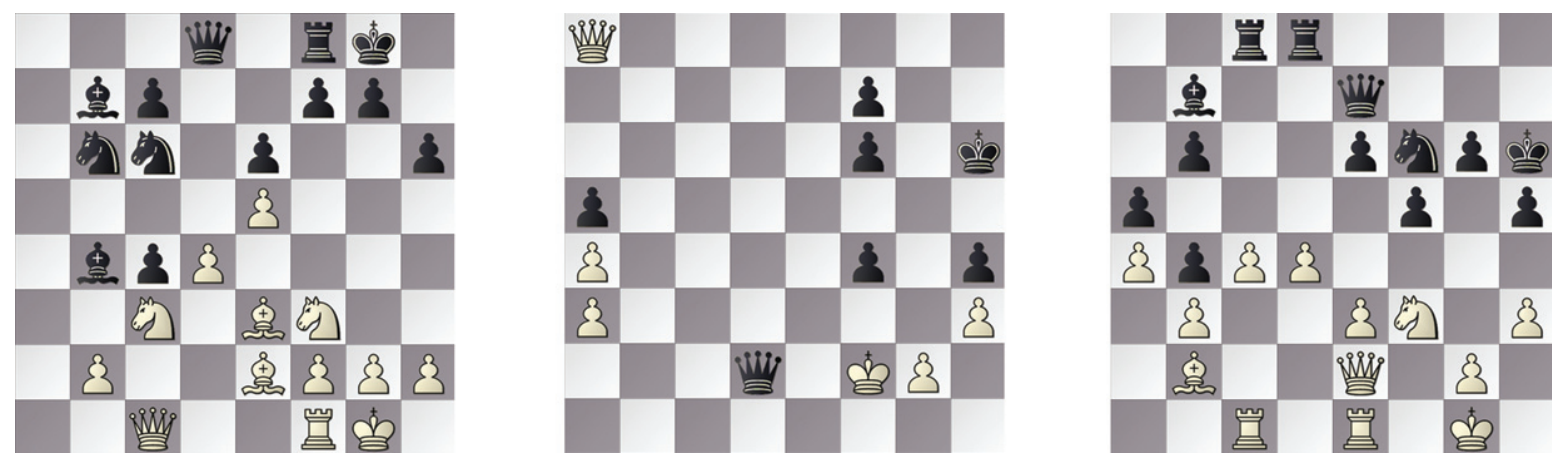

Fig. 8. R8: a) JoNny - RAPTOR 16w, b) HiArcs - Komodo 80w and c) SHREDDER - GridGinkgo 27w.

Hiarcs - Komodo was an old-style Caro-Kann game. Having seen the whole game it is perhaps best to call it the game of double pawns and triple pawns. It started in the opening when White took the knight on a6 with its bishop. Black tried to take the initiative and looked for a weak spot in the white position. 
There were two or three such spots but they were unreachable. This implied that the fight was quiet balanced. At one moment Black seemed to be in the lead but White managed to annihilate all threats. This pattern of Black attempting to find weak spots and White defending all the spots continued up to the end of the game. There, a fascinating finish was prepared. After 79. ... Qd2+, see Fig. 8b, White made the wrong choice. It should have played 80. Kf1 but instead played the unfortunate move $\mathbf{8 0 .}$ Kg1. The difference was that Kf1 draws and Kg1 loses. As the game continued Black played well and White had no opportunity to stop the avalanche.

Nowadays, programs are able to look far ahead. Thus, situations which are complex for human beings may not be complex for programs because they look over the complexities to new quiet situations. This happened in the game SHREDDER - GRIDGINKGO. After a quiet Semi Slav opening both players positioned their pieces on squares thought to be the best ones. In a complex position SHREDDER played 27. e4, see Fig. 8c, with the aim of penetrating the black queenside, in particular capturing pawn b6. Humans will have difficulties in computing the value of the new position but computers know precisely what they are aiming at. After the first part of this combination a second part started in which rooks and more pawns disappeared from the board. The third step was an indirect exchange of another piece. It is fascinating to see how a straightforward end game was the result of this battle. The game ended in a draw.

Standings: 1 Jonny 61/2, 2 Komodo 6, 3 Shredder 51⁄2, 4 GridGinkgo 3, 5 Hiarcs 2 and 6 Raptor 1.

Round 9: SHREDDER - JONNy 1/2-1/2 (D46), GRIDGINKGO - HiARCS 1/2-1/2 (B11), KOMODO - RAPTOR 1-0 (A28).

SHREDDER - JONNY was a game between two very familiar contestants. Still the authors of the programs have the right spirit, to win a game even from a friendly opponent. However enthusiasm in itself is not sufficient and during the game there was no opportunity for special initiatives. In the position of Fig. 9a, taking the e-pawn is impossible since at the end of the combination White has as a good defense $\mathrm{Bd} 3 \mathrm{xg} 6+$, winning a rook on $\mathrm{d} 8$. As the game then progressed, there were indirect exchanges of material and some were even impressive but all in all they did not change the final result. A draw was agreed after 48 moves.
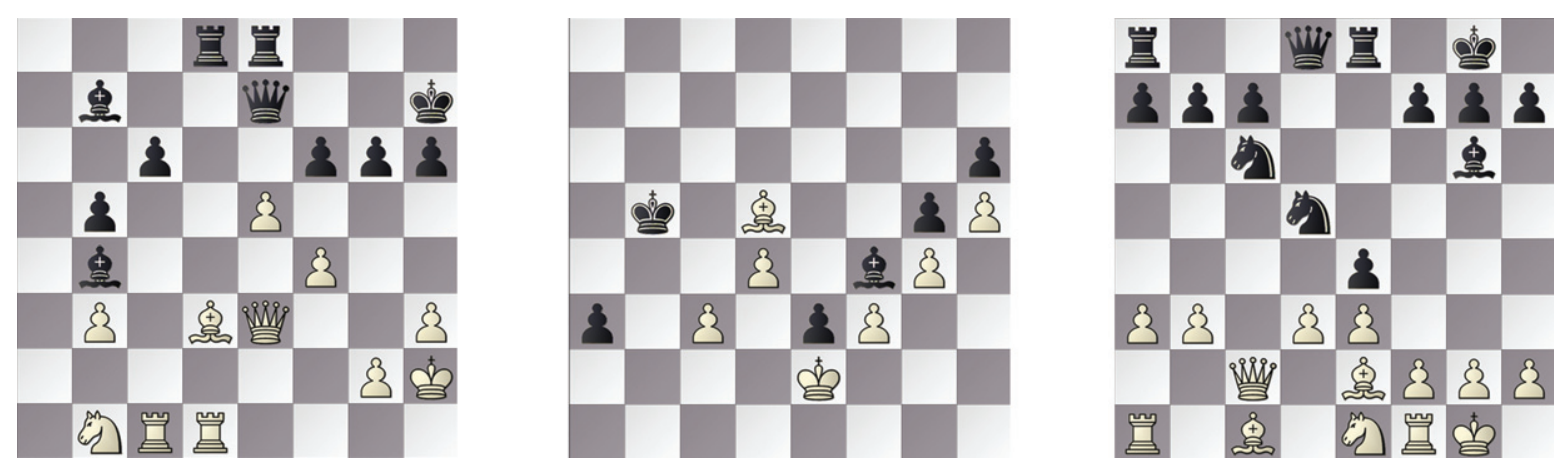

Fig. 9. R9: a) SHredDer - Jonny 31w, b) GridGinkgo - Hiarcs $106 \mathrm{~b}$ and c) Komodo - Raptor $16 \mathrm{~b}$.

GRIDGINKGO - HiARCS was a fascinating game for the players, and for the spectators it is an exercise in playing the complete sequence of moves. For more than one hundred moves the players showed that they have equal strength. Of course many small details can be highlighted but while 
the finer details may be of interest to programmers, they may not be to the general public. The game started equal and finished in the deadlocked draw of Fig. 9b, a well deserved result for both sides.

KOMODO - RAPTOR was in contrast a game for the public. Not enormously exciting but entertaining and very instructive. The lesson learned came from the observation that three pieces are superior to a queen. Black thought it had a good deal by starting a nice combination with 15. ... e4. White replied 16. b3 and Black believed it could start its combination as in Fig. 9c with 16. ... exd3. Then 17. Bxd3 Ndb4 18. axb4 Nxb4 followed and now White had a surprise in store with 19. Bxg6 sacrificing the queen for three pieces. It was a good decision and although Black delayed the loss somewhat, the win for White was unavoidable. Very well played by KomoDo.

Standings: 1= Komodo and Jonny 7, 3 Shredder 6, 4 GridGinkgo 31/2, 5 Hiarcs 21/2 and 6 RAPTOR 1.

Round 10: JONNY - KOMODO 1/2-1/2 (A88), RAPTOR - GRIDGINKGo 1/2-1/2 (B21), HiARCS - SHREDDER 0-1 (B85).

JONNY - KoMODO was a fight between the two leaders, both with 7 points from 9. This game could have determined the World Champion for 2016 but in fact it was just the first of six games in a row. The opening was the Dutch Defense, Leningrad variation. Programs of this playing strength have extensive opening books and usually find their way easily. That was also the case here. Even so, both players aimed to win this last game of the tournament proper. After some exchanges White started to play inventively but Black countered wholeheartedly. Figure 10a highlights a crucial position after 23. ... f3. White decided to sacrifice a piece in order to pin its faith on the progress of the two passed pawns on the queenside.

The overall result was that White had three pawns whereas Black had the bishop. Was this sufficient for the win? As the game went on it turned out that the two passed pawns on the queenside were very dangerous. They could only be stopped for a high price. When people replay the game they can enjoy its intricacies in the context of the later games between these two. As it went on the board we saw the following: the two pawns were dangerous but not enough. They certainly compensated for the piece sacrificed but were not sufficient for a win. A draw was the final result which of course meant a play-off between these contestants. Tables 2-4 provide the detailed scores.
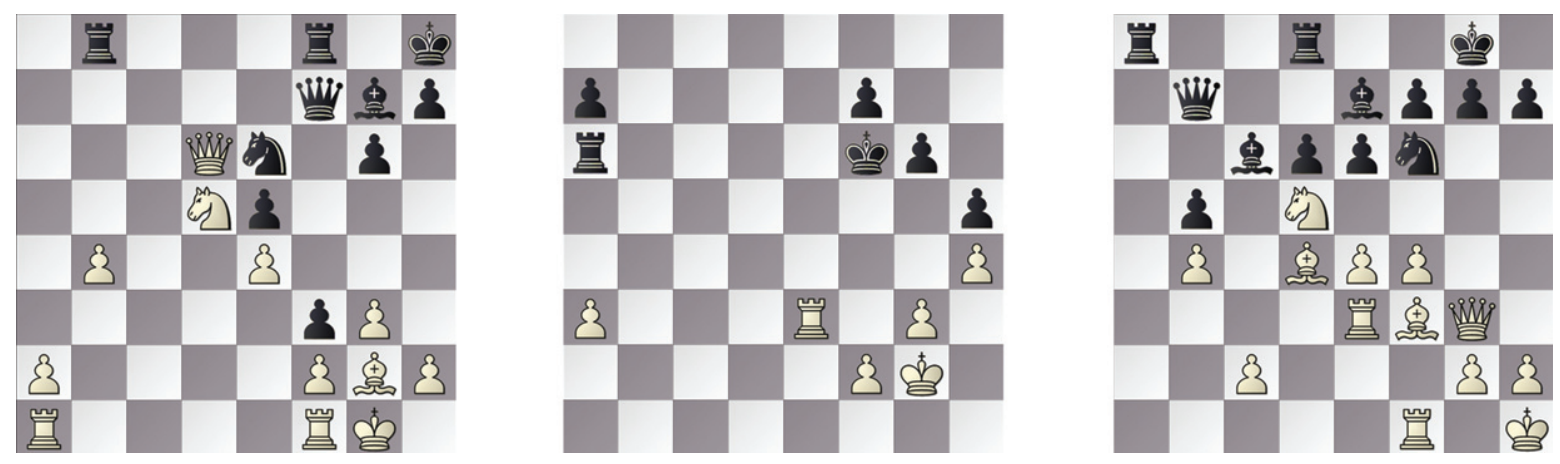

Fig. 10. R10: a) JONnY - Komodo 24w, b) RAPTOR - GridGinkgo 36w and c) Hiarcs - ShredDer 23 b. 
The game RAPTOR - GRIDGINKGO was a clear last round game. The computers had done their utmost during the tournament and now it was time for a fast game with not so many complications. Playing quickly and exchanging all that was possible without looking for complications was the order of the day. The result was a draw as in Fig. 10b which left both players happy.

The game HiARCS - SHREDDER was still important for the final ranking. It started with a Sicilian opening following a normal scheme. White had a good position but Black countered intelligently and made several good decisions. Black was on the alert when White started to challenge directly with the sacrifice of a piece. Fig. 10c illustrates the position after 23. Nd5. The continuation was exciting: 23. ... exd5 24. exd5 Bxd5 25. Rxe7 Qxe7 26. Bxd5 Rac8 27. Re1 Qxe1 28. Qxe1 Nxd5. The resulting position was evaluated as favorable to Black, sufficient to lead to a win. The final material balance was a queen against two rooks with the rooks proving to be superior.

\section{Play-offs}

As stated above, a play off between KoMODO and JONNY was required to determine the world champion. In the first phase, the playing tempo was $45^{\prime}+15^{\prime}$ /move for each side. Both games were drawn which necessitated a second phase. The playing time quickened to $5^{\prime}+5^{\prime} \prime /$ move for each side. Again, the two games were drawn so play continued with a third phase with a tempo of $3 \prime+5 \% /$ move for each side. This was decisive, the first game being drawn and the second game being won by Komodo. Thus, Komodo, once designed and implemented by Don Dailey, became the World Computer Chess Champion 2016. Our congratulations to the team and to Don's widow.

Play-off, phase 1: KOMODO - JONNY 1/2-1/2 (C53), JONNY - KOMODO 1/2-1/2 (A88).

The first game was an exciting one but started quietly with an Italian Giuco Piano. Soon after the opening both programs regrouped their pieces and a real battle took place. Black sacrificed its queen for a rook and a piece: moreover it captured some pawns as extra compensation. Nevertheless the white queen was quite active and it was difficult for Black to exploit its dynamically distributed pieces as a force that could make a difference. Finally White concluded the game with a queen sacrifice, see the position of Fig. 11a, forcing a stalemate draw.

The second game also had a surprise for the spectators as on move 28 White sacrificed the exchange, see Fig. 11b. Jonny captured an additional pawn and that was all. In fact, JonNy had a rook, two bishops and a pawn. That is usually considered as a weaker material force than two rooks and one
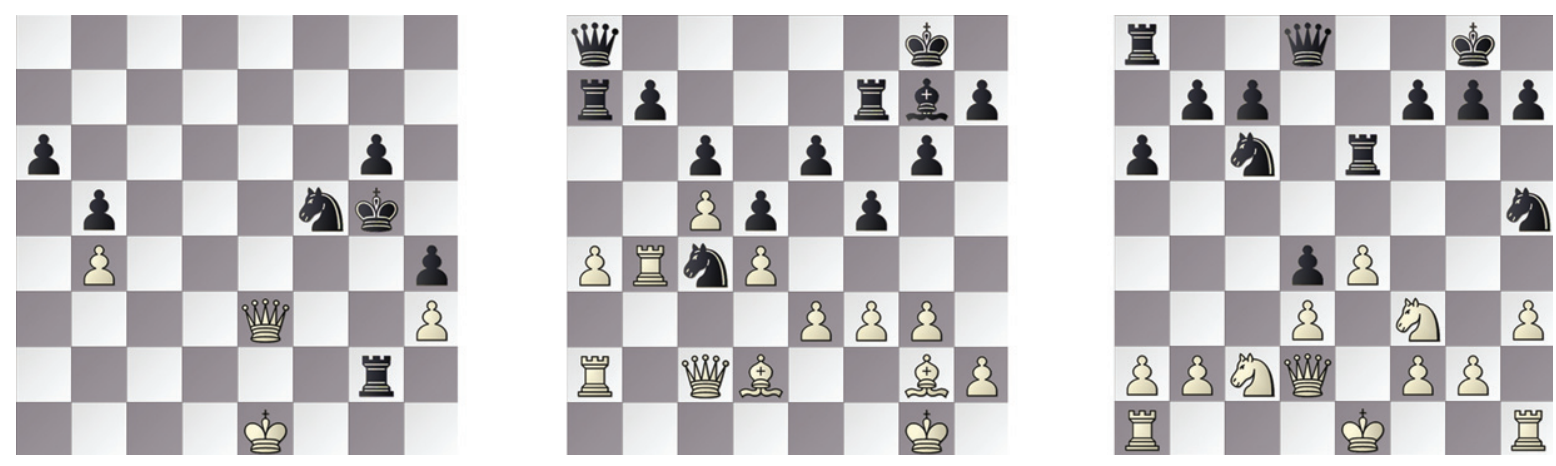

Fig. 11. PO: a) 1.1 Komodo - Jonny 53b, b) 1.2 Jonny - Komodo 28w and c) 3.2 Komodo - Jonny 17 w. 
Tables 2-4

The WCCC 2016 cross-table, results per round and progress per round

\begin{tabular}{|lcccccccccccc|}
\hline$\#$ & Program & $\mathbf{K}$ & $\mathbf{J}$ & $\mathbf{S}$ & $\mathbf{G}$ & $\mathbf{H}$ & $\mathbf{R}$ & $\mathbf{W}$ & $\mathbf{D}$ & $\mathbf{L}$ & Score S-Bgr \\
$\mathbf{1}$ & KOMODO & & $1,1 / 2$ & $1 / 2,1 / 2$ & $1,1 / 2$ & 1,1 & $1 / 2,1$ & 5 & 5 & 0 & $71 / 2$ & 31.50 \\
$\mathbf{2}$ & JONNY & $0,1 / 2$ & & $1,1 / 2$ & $1 / 2,1$ & 1,1 & 1,1 & 6 & 3 & 1 & $71 / 2$ & 28.25 \\
$\mathbf{3}$ & SHREDDER & $1 / 2,1 / 2$ & $0,1 / 2$ & & $1,1 / 2$ & 1,1 & 1,1 & 5 & 4 & 1 & 7 & 25.25 \\
$\mathbf{4}$ & GRIDGINKGO & $0,1 / 2$ & $1 / 2,0$ & $0,1 / 2$ & & $1 / 2,1 / 2$ & $1,1 / 2$ & 1 & 6 & 3 & 4 & 15.75 \\
$\mathbf{5}$ & HIARCS & 0,0 & 0,0 & 0,0 & $1 / 2,1 / 2$ & & $1,1 / 2$ & 1 & 3 & 6 & $21 / 2$ & 6.25 \\
$\mathbf{6}$ & RAPTOR & $1 / 2,0$ & 0,0 & 0,0 & $0,1 / 2$ & $0,1 / 2$ & & 0 & 3 & 7 & $11 / 2$ & 7.00 \\
\hline
\end{tabular}

\begin{tabular}{|lccccccccccc|}
\hline$\#$ & Program & r1 & r2 & r3 & r4 & r5 & r6 & r7 & r8 & r9 & r10 \\
$\mathbf{1}$ & KOMODO & $4 \mathrm{w} 1$ & $3 \mathrm{~b}^{1 / 2}$ & $5 \mathrm{w} 1$ & $6 \mathrm{~b}^{1 / 2}$ & $2 \mathrm{w} 1$ & $4 \mathrm{~b}^{1 / 2}$ & $3 \mathrm{w}^{1 / 2}$ & $5 \mathrm{~b} 1$ & $6 \mathrm{w} 1$ & $2 \mathrm{~b}^{1 / 2}$ \\
$\mathbf{2}$ & JONNY & $5 \mathrm{~b} 1$ & $4 \mathrm{w}^{1 / 2}$ & $6 \mathrm{~b} 1$ & $3 \mathrm{w} 1$ & $1 \mathrm{~b} 0$ & $5 \mathrm{w} 1$ & $4 \mathrm{~b} 1$ & $6 \mathrm{w} 1$ & $3 \mathrm{~b}^{1 / 2}$ & $1 \mathrm{w}^{1 / 2}$ \\
$\mathbf{3}$ & SHREDDER & $6 \mathrm{~b} 1$ & $1 \mathrm{w}^{1 / 2}$ & $4 \mathrm{~b} 1$ & $2 \mathrm{~b} 0$ & $5 \mathrm{w} 1$ & $6 \mathrm{w} 1$ & $1 \mathrm{~b}^{1 / 2}$ & $4 \mathrm{w}^{1 / 2} 2$ & $2 \mathrm{w}^{1 / 2}$ & $5 \mathrm{~b} 1$ \\
$\mathbf{4}$ & GRIDGINKGO & $1 \mathrm{~b} 0$ & $2 \mathrm{~b}^{1 / 2}$ & $3 \mathrm{w} 0$ & $5 \mathrm{~b}^{1 / 2}$ & $6 \mathrm{w} 1$ & $1 \mathrm{w}^{1 / 2}$ & $2 \mathrm{w} 0$ & $3 \mathrm{~b}^{1 / 2}$ & $5 \mathrm{w}^{1 / 2}$ & $6 \mathrm{~b}^{1 / 2}$ \\
$\mathbf{5}$ & HIARCS & $2 \mathrm{w} 0$ & $6 \mathrm{w} 1$ & $1 \mathrm{~b} 0$ & $4 \mathrm{w}^{1 / 2}$ & $3 \mathrm{~b} 0$ & $2 \mathrm{~b} 0$ & $6 \mathrm{~b}^{1 / 2}$ & $1 \mathrm{w} 0$ & $4 \mathrm{~b}^{1 / 2}$ & $3 \mathrm{w} 0$ \\
$\mathbf{6}$ & RAPTOR & $3 \mathrm{w} 0$ & $5 \mathrm{~b} 0$ & $2 \mathrm{w} 0$ & $1 \mathrm{w}^{1 / 2}$ & $4 \mathrm{~b} 0$ & $3 \mathrm{~b} 0$ & $5 \mathrm{w}^{1 / 2}$ & $2 \mathrm{~b} 0$ & $1 \mathrm{~b} 0$ & $4 \mathrm{w}^{1 / 2}$ \\
\hline
\end{tabular}

\begin{tabular}{|c|c|c|c|c|c|c|c|c|c|}
\hline & ro & 1 & r3 $\quad$ r4 & r5 & r6 & $\mathbf{r}$ & r8 & & \\
\hline & & & & & $4^{1} / 2$ & & & & \\
\hline & & & 12 & $J$ & & $51 / 2$ & $61 / 2$ & & \\
\hline & & $1 / 2$ & $21 / 2 \quad 2^{1 / 2}$ & 3 & $1 / 2$ & 5 & $51 / 2$ & & \\
\hline & & 11 & $1 / 2$ & & 2 & $21 / 2$ & 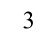 & & 4 \\
\hline & & 1 & $1 \quad 1 \frac{1}{2}$ & $1 \frac{1 / 2}{2}$ & $1 \frac{1}{2}$ & 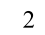 & 2 & $2^{1 / 2}$ & $2^{1 / 2}$ \\
\hline & APTOR & 0 & 0 & $1 / 2$ & $1 / 2$ & 1 & 1 & & \\
\hline
\end{tabular}

bishop. However in the game it turned out to be of equal value. Later on Black felt forced to return the material after which an equal position resulted and a draw was agreed.

Play-off, phase 2: KoMODO - JONNY 1/2-1/2 (C65), JONNY - KOMODO 1/2-1/2 (D26).

The second play-off consisted of two blitz games. The first game was a blitz game in two senses: the game was soon over and the exchange of pieces happened in quick time. The second game was rather similar to the first one: exchange of pieces and no real complications for either contender.

Play-off, phase 3: JoNNY - KoMOdo 1/2-1/2 (D26), KOMODO - JONNY 1-0 (C53).

The first game of the third play-off was a worthy successor to the previous four games. Play was acceptable, the outcome also, but the outcome was not decisive as it was a draw. The final game brought the decision. The opening was a Giuco Piano and the game followed this name. In the position of Fig. 11c White started to ponder: JoNNY expected that KomODO would castle to the king side. After that move the position would have been considered equal. To JonNY's surprise KomoDo castled to the queenside. That was seen as a better strategic decision as White had a majority of pawns on the kingside, namely 4 (e-h) against 3 (f-h). The idea was to get these pawns moving towards the black king. If we look where the black pawns stand, with respect to the minority on the kingside than we see the pawn on c7. This pawn is clearly inferior to the white pawn on the kingside. So, in summary terms, it is not surprising that White won this game convincingly and deservedly.

Congratulations to the new World Champion Komodo.

\section{REFERENCES}

CPW (2016a). http://preview.tinyurl.com/ph94pc5. The CPW biography of the late Don Dailey.

CPW (2016b). http://preview.tinyurl.com/oq5bp6x. The CPW biography of Erdogan Günes.

CPW (2016c). http://preview.tinyurl.com/o934x5k. The CPW biography of Timo Haupt.

CPW (2016d). http://preview.tinyurl.com/jk3ws3z. The CPW biography of Kai Himstedt.

CPW (2016e). http://preview.tinyurl.com/zlhhpur. The CPW biography of Robert Hyatt. 
CPW (2016f). http://preview.tinyurl.com/pd3wglj. The CPW biography of Larry Kaufman GM. CPW (2016g). http://preview.tinyurl.com/p7qmuor. The CPW biography of Mark Lefler.

CPW (2016h). http://preview.tinyurl.com/qej8djl. The CPW biography of Stefan Meyer-Kahlen. CPW (2016i). http://preview.tinyurl.com/q6hmhmj. The CPW biography of Frank Schneider. CPW (2016j). http://preview.tinyurl.com/nr74dyd. The CPW biography of Mark Uniacke. CPW (2016k). http://preview.tinyurl.com/zdjjor3. The CPW biography of Steve Webber. CPW (20161). http://preview.tinyurl.com/ozjkt73. The CPW biography of Harvey Williamson. CPW (2016m). http://preview.tinyurl.com/j8gy7jl. The CPW biography of Hans v.d. Zijden. CPW (2016n). http://preview.tinyurl.com/gs65poj. The CPW biography of Wolfgang Zugrav. CPW (2016o). http://preview.tinyurl.com/lxh7mh4. The CPW biography of Johannes Zwanzger. CPW (2016p). http://chessprogramming.wikispaces.com/Ginkgo. The CPW biography of Ginkgo. CPW (2016q). http://chessprogramming.wikispaces.com/Hiarcs. The CPW biography of Hiarcs. CPW (2016r). http://chessprogramming.wikispaces.com/Jonny. The CPW biography of Jonny. CPW (2016s). http://chessprogramming.wikispaces.com/Komodo. The CPW biography of Komodo. CPW (2016t). http://chessprogramming.wikispaces.com/Raptor. The CPW biography of Raptor. CPW (2016u). http://chessprogramming.wikispaces.com/Shredder. The CPW biography of Shredder.

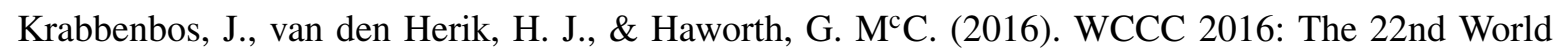
Computer Chess Championship. ICGA J, 39(1), 45-57, http://centaur.reading.ac.uk/67922/ 